Original research article

\title{
Insulin degludec and glutamine dipeptide modify glucose homeostasis and liver metabolism in diabetic mice undergoing insulin-induced hypoglycemia
}

\author{
Camila Bataglini ${ }^{1}$, Isabela Ramos Mariano ${ }^{2}$, Sílvia Carla Ferreira Azevedo ${ }^{3}$, Valder Nogueira Freire ${ }^{4}$, \\ Maria Raquel Marçal Natali ${ }^{3}$, Maria Montserrat Dias Pedrosa ${ }^{2}$, Rosane Marina Peralta ${ }^{1}$, \\ Anacharis B. Sá-Nakanishi ${ }^{1}$, Lívia Bracht ${ }^{1}$, Vilma A. Ferreira Godoy ${ }^{2}$, Adelar Bracht ${ }^{1}$, \\ Jurandir Fernando Comar ${ }^{1 *}$ \\ ${ }^{1}$ State University of Maringá, Department of Biochemistry, Maringá, PR, Brazil \\ 2 State University of Maringá, Department of Physiological Sciences, Maringá, PR, Brazil \\ ${ }^{3}$ State University of Maringá, Department of Morphological Sciences, Maringá, PR, Brazil \\ ${ }^{4}$ Federal University of Ceará, Department of Physics, Fortaleza, CE, Brazil
}

\section{Abstract}

This study investigated whether a 30-day co-treatment with $1 \mathrm{~g} / \mathrm{kg}$ glutamine dipeptide (GdiP) and $1 \mathrm{U} / \mathrm{kg}$ regular (rapid acting) or $5 \mathrm{U} / \mathrm{kg}$ degludec (long acting) insulins modifies glucose homeostasis and liver metabolism of alloxan-induced type 1 diabetic (T1D) male Swiss mice undergoing insulin-induced hypoglycemia (IIH). Glycemic curves were measured in fasted mice after IIH with $1 \mathrm{U} / \mathrm{kg}$ regular insulin. One hour after IIH, the lipid profile and AST and ALT activities were assayed in the serum. Morphometric analysis was assessed in the liver sections stained with hematoxylin-eosin and glycolysis, glycogenolysis, gluconeogenesis and ureagenesis were evaluated in perfused livers. T1D mice receiving GdiP or the insulins had a smaller blood glucose drop at 60 minutes after IIH, which was not sustained during the subsequent period up to 300 minutes. The 30-day treatment of T1D mice with insulin degludec, but not with regular insulin, improved fasting glycemia, body weight gain and serum activity of AST and ALT. Treatments with insulin degludec, GdiP and insulin degludec + GdiP decreased the liver capacity in synthesizing glucose from alanine. GdiP, in combination with both insulins, was associated with increases in the serum triglycerides and, in addition, regular insulin and GdiP increased AST and ALT activities, which could be the consequence of hepatic glycogen overload. GdiP and the insulins improved the IIH, although to a small extent. Caution is recommended, however, with respect to the use of GdiP because of its increasing effects on serum triglycerides and AST plus ALT activities.
\end{abstract}

Keywords: Gluconeogenesis; Glutamine dipeptide; Insulin degludec; Insulin-induced hypoglycemia; Liver metabolism; Type I diabetes

\section{Highlights:}

- Type I diabetic mice received insulin degludec and glutamine dipeptide (GdiP) for 30 days.

- Hypoglycemia was induced in fasted diabetic mice with an injection of regular insulin.

- GdiP (1 g/kg) and insulin degludec improved the insulin-induced hypoglycemia (IIH).

- GdiP and degludec decresed the liver gluconeogenesis from alanine following IIH.

- GdiP increased the serum activity of liver transaminases and caution is recommended.

\section{Abbreviations:}

ALT, alanine aminotransferase; AST, aspartate aminotransferase; AUC, area under the curve; GdiP, glutamine dipeptide; IIH, insulininduced diabetes; $\mathrm{KH}$, Krebs-Henseleit buffer; T1D, type 1 diabetes

\section{Introduction}

In type 1 diabetes mellitus (T1D), the daily replacement of insulin is mandatory for preventing hyperglycemia, which occurs mainly as a consequence of decreased peripheral glucose uptake and upregulation of hepatic gluconeogenesis (Pra- sath et al., 2014). There are currently many types of insulin available, which differ mainly in how long they are active in the body (Silver et al., 2018). The most common type used is regular insulin, a short-acting insulin with bolus activity and effects lasting 6-8 h (American Diabetes Association, 2019). A shortcoming of regular insulin is that it can lead to alternating episodes of hypo- and hyperglycemia. Alternatively, long-

\footnotetext{
* Corresponding author: Jurandir Fernando Comar, State University of Maringá, Department of Biochemistry, Colombo Avenue 5790, 87020-900 Maringá, Brazil; e-mail: jfcomar@uem.br http://doi.org/10.32725/jab.2021.025

Submitted: 2020-12-03 • Accepted: 2021-10-21 • Prepublished online: 2021-11-02

J Appl Biomed 19/4: 210-219 • EISSN 1214-0287 • ISSN 1214-021X

(c) 2021 The Authors. Published by University of South Bohemia in České Budějovice, Faculty of Health and Social Sciences.

This is an open access article under the CC BY-NC-ND license.
} 
-acting or basal insulins have lower plasma concentration peaks and longer acting periods. The long-acting insulin degludec (25-h half-life) distinguishes itself for being able to maintain a more constant level of serum insulin and lower glycemic variability (Heise et al., 2012). Degludec is an insulin analogue that undergoes complexation with zinc and, after injection, forms a soluble depot in the subcutaneous tissue with a slow release of insulin into the systemic circulation (Jonassen et al., 2012).

The efficient regulation of blood glucose in T1D requires a rigid schedule of insulinization based on multiple daily doses of prandial insulins or continuous subcutaneous insulin infusion, or even the combination of basal and fast-acting insulins (American Diabetes Association, 2017). Nevertheless, most insulin therapies are associated with episodes of insulin-induced hypoglycemia (IIH) (Cryer, 2008). In healthy individuals, IIH inhibits the secretion of endogenous insulin and stimulates the secretion of counterregulatory hormones, particularly glucagon, catecholamines and cortisol, which in turn, stimulate the hepatic production of glucose and reduce its peripheral utilization, thus increasing blood glucose (Cryer, 2008). In T1D individuals, the exogenous insulin does not decrease as blood glucose decreases and, furthermore, the secretion of counterregulatory hormones is lost over time (McCrimmon and Sherwin, 2010).

L-Glutamine plays a significant role in a number of physiological processes, such as the transportation of blood ammonia and blood $\mathrm{pH}$ regulation (Cruzat et al., 2018). This amino acid has also been reported to have anti-inflammatory and immunomodulatory activities (Cruzat et al., 2018). In fact, L-glutamine supplementation has been reported to improve glucose homeostasis of individuals with chronic diseases, including T1D (Darmaun et al., 2019; Stehle et al., 2017).

Dietary nutrients absorbed by the enterocytes first pass through the liver before reaching the systemic circulation. This strategic position of the liver, between the gastrointestinal tract and peripheral circulation, gives it a pivotal role in the metabolic homeostasis (Sharabi et al., 2015). Glutamine is also a relevant substrate for hepatic gluconeogenesis, a crucial metabolic pathway for euglycemic maintenance after glycogen depletion during fasting and hypoglycemic episodes (Cruzat et al., 2018). In this regard, normoglycemic mice, but not T1D mice, orally receiving glutamine shortly after the IIH had higher hepatic gluconeogenesis and greater ability to recover blood glucose than mice receiving alanine or even glucose (Bataglini et al., 2017; Nunes Santiago et al., 2013). However, it is not known if long-term supplementation with glutamine attenuates episodes of IIH in T1D mice. Therefore, this study investigated whether 30-day supplementation with glutamine dipeptide (GdiP) alone or in combination with insulin degludec or regular insulin therapy modifies the glycemic homeostasis and hepatic metabolism of T1D mice during IIH. The dipeptide L-alanyl-L-glutamine, known as glutamine dipeptide, has been widely used in clinical practice as a substitution for free glutamine because, unlike the latter, the dipeptide is not consumed by intestinal cells (Raizel and Tirapegui, 2018).

\section{Materials and methods}

\section{Animals and induction of diabetes}

Male Swiss mice weighing around 25 g (50 days old) were obtained from the Center of Animal Breeding of the State University of Maringá (UEM) and maintained under standard laboratory conditions and a regulated $12 \mathrm{~h}$ light/dark cycle. Mice were fed ad libitum with a standard laboratory diet. Mice fasted for $15 \mathrm{~h}$ were diabetized with alloxan (180 mg/kg). Four days after, fasting blood glucose was measured in blood collected by tail incision (glucometer and glycophyte Optium Xceed ${ }^{\circledR}$, Abbott). Animals with fasting blood glucose higher than $300 \mathrm{mg} / \mathrm{dl}$ were considered T1D (Federiuk et al., 2004). All procedures were performed as recommended by the Brazilian Council for the Control of Animal Experimentation (CONCEA) and are in accordance with the European Directive 2010/63/ EU. The study was approved by the Ethics Committee for Animal Use of UEM (protocol number 1334110116).

\section{Experimental design and treatment}

Diabetic mice were distributed into six groups $(n=7$ per group): D, which received saline; DG, which received glutamine dipeptide (GdiP); DIR, which received regular insulin; $D I R+G$, regular insulin and GdiP; DIT, insulin degludec; and DIT+G, insulin degludec and GdiP. Seven non-diabetic mice served as controls (C). For 30 days the animals received daily $1 \mathrm{~g} / \mathrm{kg}$ GdiP (oral gavage) or saline and, for the same period, saline (s.c.) or $1 \mathrm{U} / \mathrm{kg}$ i.p. regular insulin (Humulin ${ }^{\circledR} \mathrm{R}$; Eli Lilly) or 5 U/kg s.c. insulin degludec (Tresiba ${ }^{\circledR}$ FlexTouch ${ }^{\circledR}$, Novo Nordisk $\left.^{\circledR}\right)$. The dose of insulin degludec (5 U/kg) was based on a previous study which revealed that this dose led to stable blood glucose in mice (Bataglini et al., 2017). This dose would correspond to a human dose of $0.4 \mathrm{U} / \mathrm{kg}$ as given by the body surface area normalization method (Reagan-Shaw et al., 2007).

\section{Glycemic curves}

After treatment for 30 days, $15 \mathrm{~h}$ fasted T1D animals received regular insulin ( $1 \mathrm{U} / \mathrm{kg}$ ) to induce $\mathrm{IIH}$ at 8 a.m. (time 0 ). Blood samples were collected from the tail at times $0,15,30,60,120$, 180, 240 and $300 \mathrm{~min}$ to measure blood glucose. This procedure aimed to characterize the periods of lower blood glucose and blood glucose recovery. This same protocol was conducted to evaluate the response of T1D animals during IIH to the counterregulatory hormones glucagon $(0.02 \mathrm{mg} / \mathrm{kg})$, cortisol (20 mg/kg) or adrenaline ( $1 \mathrm{mg} / \mathrm{kg})$. For this, the hormones were administered (s.c.) $15 \mathrm{~min}$ after IIH.

\section{Liver perfusion}

After 30-day treatment, $15 \mathrm{~h}$ fasted control and T1D mice received regular insulin to induce $\mathrm{IIH}$ and cortisol $15 \mathrm{~min}$ later. One hour after IIH, the non-recirculating liver perfusion was performed as previously described (Broetto-Biazon et al., 2009; Nunes Santiago et al., 2013). After an initial period of $10 \mathrm{~min}$ of perfusion to stabilize the preparation, samples of the effluent perfusion fluid were collected at five-minute intervals and analyzed for their content of glucose, lactate, pyruvate, ammonia and urea (Bergmeyer, 1974). During this period, liver perfusion was performed as follows: $30 \mathrm{~min}$ with Krebs-Henseleit buffer (KH), 30 min with $\mathrm{KH}$ plus glucagon $(1.0 \mu \mathrm{M}), 30 \mathrm{~min}$ with $\mathrm{KH}$ plus L-alanine $(5.0 \mathrm{mM})$ and another $30 \mathrm{~min}$ with $\mathrm{KH}$. L-Alanine was used as substrate because it is one of the main gluconeogenic precursors in humans and rodents and, in contrast to glutamine, it is rapidly converted into glucose and its deamination does not require previous activation by ammonium in the liver (Comar et al., 2010). Fig. 2 illustrates the perfusion protocol.

\section{Tissue collection and processing}

After treatment for 30 days, animals fasted for $15 \mathrm{~h}$ were anesthetized with Thionembutal ${ }^{\circledR}(30 \mathrm{mg} / \mathrm{kg}$ i.p.) and lidocaine (10 mg/kg) and blood was collected by cardiac puncture, centrifuged and serum separated to measure total cholesterol, triglycerides, and the activity of ALT and AST. Next, a vertical 
laparotomy was performed and the liver removed for morphometric analysis.

For histological processing, the liver samples were fixed in $10 \%$ Bouin solution, dehydrated in ethanol gradient, cleared in xylol and embedded in paraffin blocks. Semi-serial $6 \mu \mathrm{m}$ thick cross-sections were prepared with a rotary microtome (Leica RM2245), mounted on slides and stained with hematoxylin-eosin.

\section{Morphometric analyses}

Morphometric analyses were done with images of the liver parenchyma in the region near the central vein. Images were captured from an optical microscope (Olympus BX41 ${ }^{\circledR}$, Japan) with a QColor3 ${ }^{\circledR}$ camera (Olympus American INC, Canada), coupled with the software Q-Capture ${ }^{\circledR}$. Hepatocytes number and area were evaluated using the program Image-Pro Plus ${ }^{\circledR}$ 4.5 (Media Cybernetics). For quantifying the hepatocytes areas, 200 hepatocytes per animal were examined, totaling 1000 hepatocytes per group $\left(\mu \mathrm{m}^{2}\right)$. For the number of hepatocytes, 30 images per animal were counted, totalling $150 \mathrm{im}$ ages per group (12.592.39 $\mu \mathrm{m}^{2}$ per group). The results were expressed as mean \pm SEM.

\section{Statistical analysis}

The error parameters presented in graphs and tables are standard errors of the means. Statistical analysis was done by means of GraphPad Prism Software (version 5.0). The statistical significance of the data was analyzed by means of ANOVA oneway, and a Tukey post-hoc test was applied with the 5\% level $(p<0.05)$. For histological analysis, the data were first analyzed by Kolmogorov-Smirnov test for testing normality of distribution. Subsequently, the parametric data were analyzed by ANOVA one-way and Tukey's post-hoc testing.

\section{Results}

\section{Glycemic curves and serum lipid profile}

Fig. 1A shows the results obtained with animals that received solely regular insulin to induce IIH. Fig. 1B shows other groups treated identically that received cortisol $15 \mathrm{~min}$ after IIH. The results obtained with glucagon and adrenaline are not shown because these agents decreased the blood glucose even more when compared to the diabetic mice (D) undergoing $\mathrm{IHH}$, i.e., these hormones apparently did not elicit any counterregulatory response. Only cortisol prevented the drop in blood glucose to values below those of group $\mathrm{D}$ and for this reason was used in the next procedures.

In untreated diabetic mice (D), the induction of IIH diminished the blood glucose progressively, reaching values below $100 \mathrm{mg} / \mathrm{dl}$ (Fig. 1A). At $60 \mathrm{~min}$, blood glucose was still relatively high, but it can already be considered a hypoglycemic situation because blood glucose reached less than $50 \%$ of the value before IIH and signs denoting the condition, particularly lethargy, were observed. In DIT and DIT $+\mathrm{G}$ animals, blood glucose at time 0 was even lower. The response to IIH in the DIT group was fast, i.e., a glycemic level at or slightly under $100 \mathrm{mg} / \mathrm{dl}$ was already reached after $60 \mathrm{~min}$. In the GdiP treated groups (DG, DIR+G and DIT+G), the response was delayed, as blood glucose remained relatively high at $60 \mathrm{~min}$ and a pronounced drop occurred only later. This is particularly true for DIR+G. Animals treated with regular insulin (DIR) were also less responsive to the sudden IIH.

The simultaneous administration of cortisol produced a few changes (Fig. 1B). In the DIT group the strong response to IIH at $60 \mathrm{~min}$ (with blood glucose $40 \%$ lower than in group D), was almost abolished by cortisol and the overall response of DIT was made very similar to the responses of the other groups. This result suggests that, at $60 \mathrm{~min}$, cortisol was effective in inducing a counterregulatory response.

Table 1 shows the body weight gain and serum levels of total cholesterol and triglycerides. The body weight gain during the 30 -day treatment was $36 \%$ lower in the T1D groups and even lower (64\%) in the DG group. Serum triglycerides were increased by approximately $80 \%$ in $D I R+G$ and DIT $+G$ mice. Serum cholesterol was practically not modified.

\section{Liver metabolism}

The hepatic outputs of glucose, lactate, pyruvate, urea and ammonia are shown in Fig. 2 as a function of the perfusion time. The glucose output in livers from D, DG and DIR+G was high after starting perfusion with $\mathrm{KH}$ alone, but with a continuous decline up to $30 \mathrm{~min}$. This phenomenon mainly reflects glucose release from the glycogen stores, which are usually higher in diabetic animals (Comar et al., 2016). The declining rates of glucose and lactate at the beginning of the perfusion (0-30 $\mathrm{min}$ ) can be best appreciated by evaluating the AUC, which correspond to the total amounts released during the initial $30 \mathrm{~min}$. Fig. 3 shows the amounts of glucosyl units released as glucose, lactate and pyruvate (here assumed to be an estimate of total glycogenolysis) and those diverted into glycolysis (lactate plus pyruvate), expressed as $C_{6}$ units for each condition (Castro-Ghizoni et al., 2017). Glycogenolysis was 230,470 and $140 \%$ higher in D, DG and DIR+G, respectively (compared to the controls). Glycolysis was higher in the livers of DG (150\%), but lower in the livers of DIT (40\%) and DIT+G (50\%).

In terms of the carbon flow derived from glycogen catabolism, still present at 30 min perfusion time, it superimposes on the carbon flow derived from alanine, a condition that makes interpretation difficult. In an attempt to minimize this problem, glucagon was introduced at 30-60 min to further deplete the glycogen stores (Fig. 2). Livers from DIR+G responded with a transient increase in glucose release, denoting a significant amount of degradable glycogen. For all other groups, glucose or lactate release continued to decrease until the final period of glucagon infusion.

The substitution of glucagon by alanine (at time $60 \mathrm{~min}$ ) resulted in different increases in the outputs of all metabolites, which tended to stabilize during the last min of the alanine infusion. These steady-state rates were used to calculate the metabolic fluxes dependent solely on alanine transformation by subtracting the metabolic fluxes dependent on endogenous substrates. The latter was inferred from the final base line achieved during the period between 20-30 min following cessation of alanine infusion. Fig. $4 \mathrm{~A}$ reveals that acceleration of alanine gluconeogenesis was not found irrespective of the condition. However, diminished rates of glucose production, when compared to control mice, were found in DIT and DIT $+\mathrm{G}$ $(-25 \%)$ and in DG (-33\%) mice. Treatment with regular insulin maintained the gluconeogenic activity close to that observed in the livers of control mice. The rates of lactate production (Fig. 4C) were high and close to normal in livers from $D$ and DG, and low in livers from DIR, DIR+G, DIT and DIT+G, actually very low for the latter. Pyruvate production behaved similarly (Fig. 4D), the lowest rates having occurred in the livers of DIR+G, DIT and DIT+G. The lactate to pyruvate ratio, which in the liver reflects the cytosolic $\mathrm{NADH}$ to $\mathrm{NAD}^{+}$ratio (Sies, 1982), presented several differences among the various groups (Fig. 4B). The highest ratio was in the livers of DIR+G. 
The carbon flow represented by panels A, C and D in Fig. 4, must have its counterpart in the nitrogen flow, which is shown in panels E and F. In general, the groups that presented lower rates of glucose, lactate and pyruvate production also presented lower rates of nitrogen detoxification. This is an expected phenomenon which can be best appreciated by examining Fig. 5, in which the changes in $3 C$ fluxes caused by alanine are represented in one panel (A) and the corresponding $1 \mathrm{~N}$ fluxes in the other (B). In general, lower carbon fluxes corresponded to lower nitrogen fluxes as both variables presented a relati- vely good correlation $(r=0.92)$, with a $1 \mathrm{~N} / 3 \mathrm{C}$ mean ratio of $0.921 \pm 0.044$. The expected ratio should be close to unity and thus the value that was found is a good approximation. It is clear that livers treated with insulin degludec present the lowest rates of alanine metabolism, DIT $+G$ being inferior to DIT. Apparently, the simultaneous GdiP treatment enhances the effect of insulin degludec treatment. Interestingly, the opposite occurs with regular insulin: in this case the simultaneous GdiP treatment tends to increase alanine metabolism.
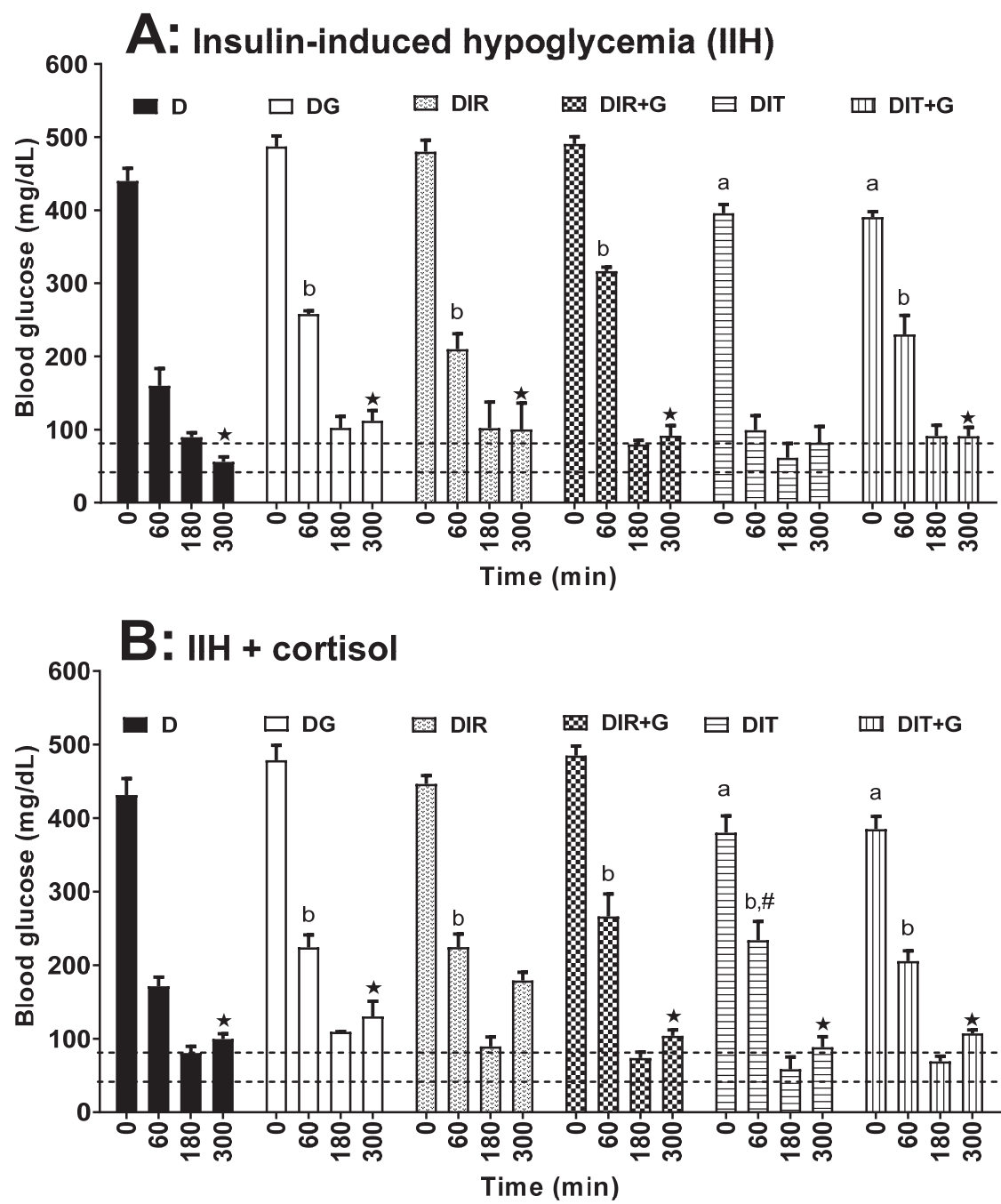

Fig. 1. Effects of 30-day treatment with glutamine dipeptide (GdiP; $1 \mathrm{~g} / \mathrm{kg})$, regular insulin (1 U/kg) or insulin degludec (5 U/kg) on glycemic curves of T1D mice during IIH (A) and IIH + cortisol (B). Symbols: D, saline; DG, GdiP; DIR, regular insulin; DIT, insulin degludec; DIR+G, regular insulin + GdiP; DIT $+G$, insulin degludec + GdiP. Values are the mean \pm SEM of 5 animals. ${ }^{a} p \leq 0.05$ for 0 min $\times 0$ min of D; ${ }^{b} p \leq 0.05$ for $60 \mathrm{~min} \times 60 \mathrm{~min}$ of $\mathrm{D} ;{ }^{*} p \leq 0.05$ for $300 \mathrm{~min} \times 60$ min intragroup. $\# p \leq 0.05$ for $\mathrm{IIH}+$ cortisol $\times \mathrm{IIH}$.

Table 1. Body weight gain, blood glucose and serum lipids of $15 \mathrm{~h}$ fasted mice after 30 -day treatment

\begin{tabular}{|c|c|c|c|c|c|c|c|}
\hline Parameter & C & $\mathrm{D}$ & DG & DIR & $\mathrm{DIR}+\mathrm{G}$ & DIT & $\mathrm{DIT}+\mathrm{G}$ \\
\hline Body weight gain $(\mathrm{g})$ & $22 \pm 1^{a}$ & $14 \pm 2^{b}$ & $8 \pm 1^{c}$ & $12 \pm 1^{b}$ & $13 \pm 1^{b}$ & $18 \pm 1^{\mathrm{a}}$ & $12 \pm 1^{b}$ \\
\hline Fasting blood glucose $\left(\mathrm{mg} \cdot \mathrm{dl}^{-1}\right)$ & $106 \pm 2^{a}$ & $439 \pm 10^{\mathrm{b}}$ & $487 \pm 13^{b}$ & $480 \pm 10^{\mathrm{b}}$ & $490 \pm 15^{\mathrm{b}}$ & $395 \pm 4^{c}$ & $390 \pm 4^{c}$ \\
\hline Triglycerides $\left(\mathrm{mg} \cdot \mathrm{dl}^{-1}\right)$ & $45 \pm 2^{\mathrm{a}}$ & $49 \pm 3^{a}$ & $49 \pm 2^{\mathrm{a}}$ & $61 \pm 5^{\mathrm{a}}$ & $90 \pm 4^{c}$ & $47 \pm 3^{\mathrm{a}}$ & $80 \pm 4^{\mathrm{b}}$ \\
\hline Total cholesterol $\left(\mathrm{mg} \cdot \mathrm{dl}^{-1}\right)$ & $94 \pm 1,6^{\mathrm{a}}$ & $103 \pm 1^{\mathrm{a}}$ & $109 \pm 6^{\mathrm{a}}$ & $67 \pm 2^{b}$ & $107 \pm 3^{\mathrm{a}}$ & $103 \pm 2^{\mathrm{a}}$ & $72 \pm 4^{\mathrm{b}}$ \\
\hline
\end{tabular}




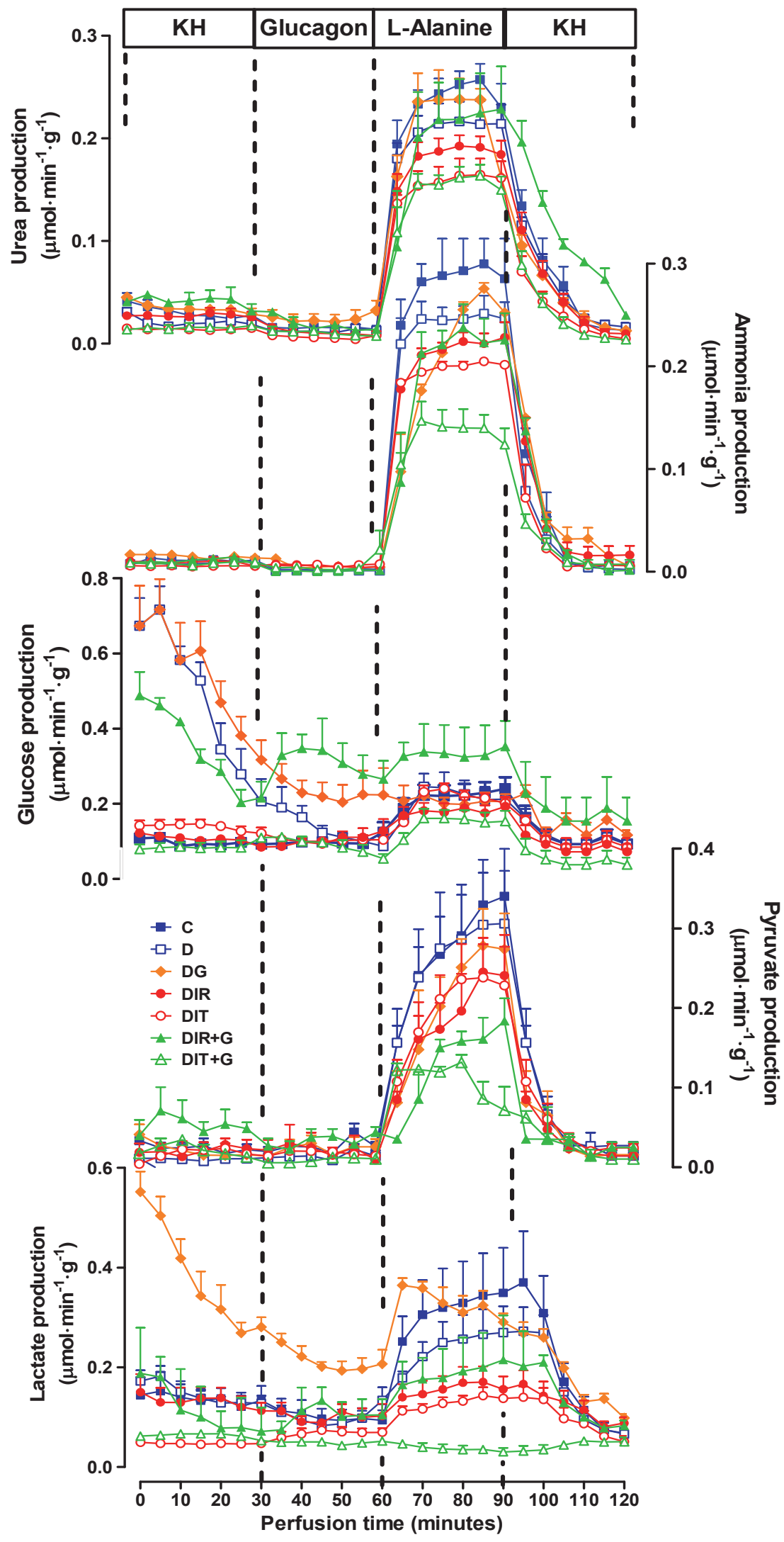

Fig. 2. Time courses of glucose, lactate, pyruvate, ammonia and urea in the perfused liver of T1D mice during IIH under various conditions. Regular insulin ( $1 \mathrm{U} / \mathrm{kg}$ ) was administered to the $15 \mathrm{~h}$ fasted mice (IIH induction) and cortisol (20 mg/kg), respectively, $1 \mathrm{~h}$ and $45 \mathrm{~min}$ prior to the liver perfusion procedure. Glucagon $(1.0 \mu \mathrm{M})$ and L-alanine $(5.0 \mathrm{mM})$ were infused in combination with $\mathrm{KH}$ buffer as shown by the horizontal bars. The abbreviations of the groups are defined in Table 1. Values are expressed as $\mu$ mol per min per g of liver tissue and they are the mean \pm SEM of 5 animals for each group. 

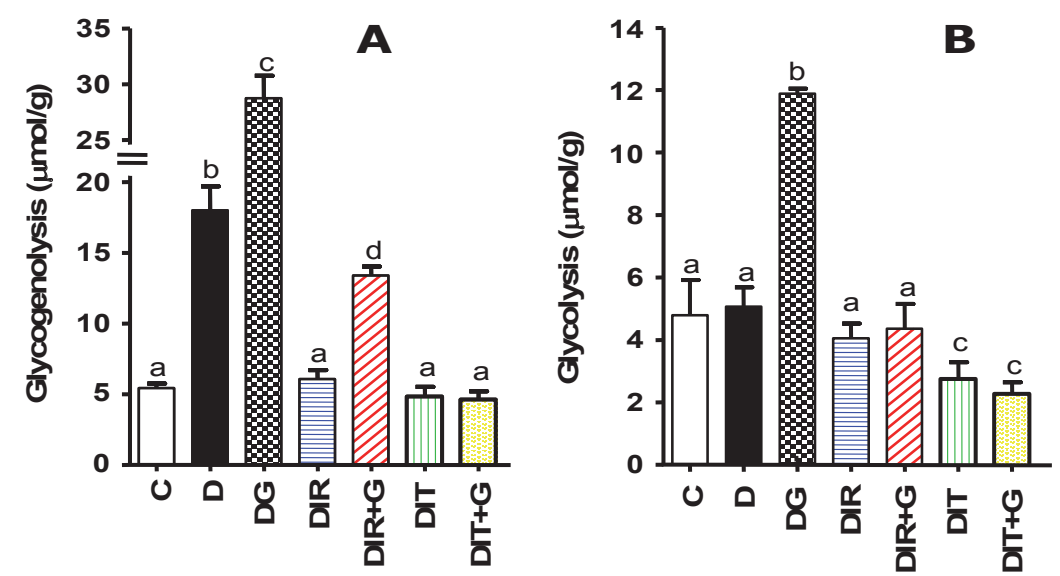

Fig. 3. Glycogenolysis and glycolysis in the perfused liver of T1D mice during IIH. The values are the area under the curve (AUC) corresponding to the 0 to 30 time interval in Fig. 2. Glycolysis was taken as (pyruvate + lactate)/2 and glycogenolysis as glucose $+[($ lactate + pyruvate)/2]. The abbreviations of the groups are defined in Table 1 . Values are the mean $\pm \operatorname{SEM}(n=5)$. Values with different letters in the same panel are different $(p \leq 0.05 C)$.
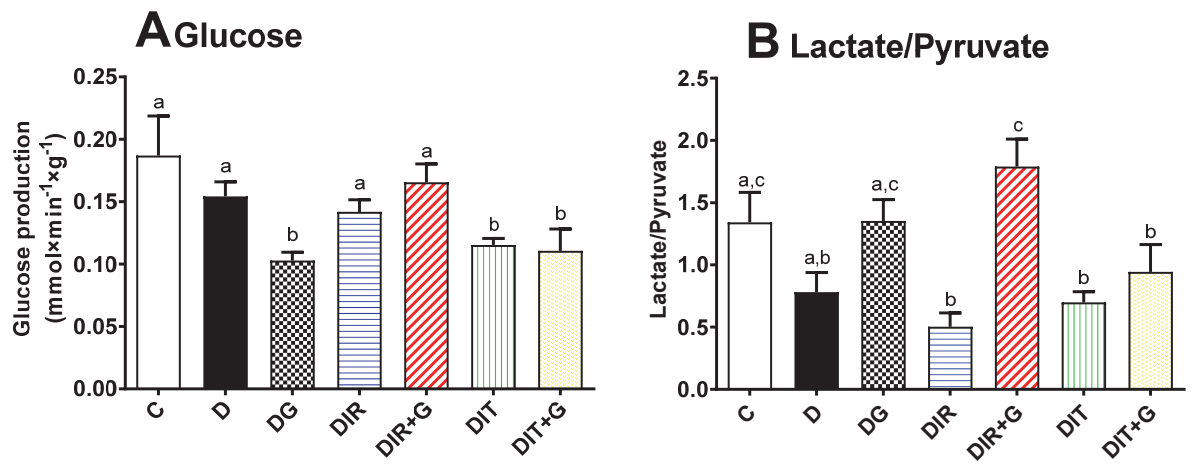

\section{Lactate}

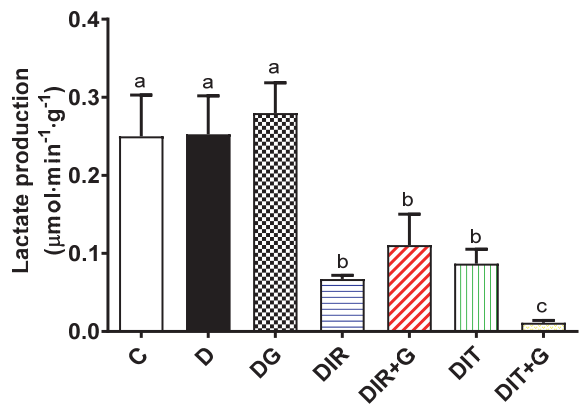

D Pyruvate

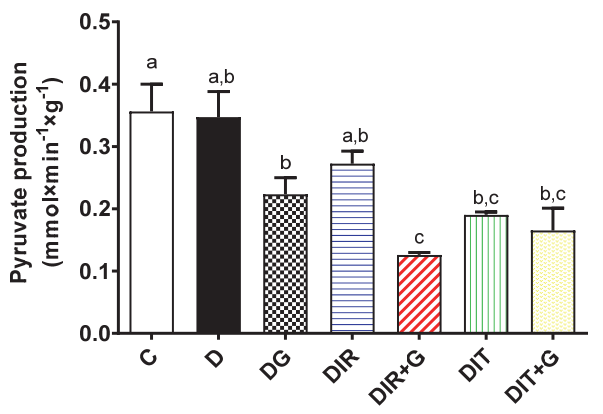

\section{EAmmonia}

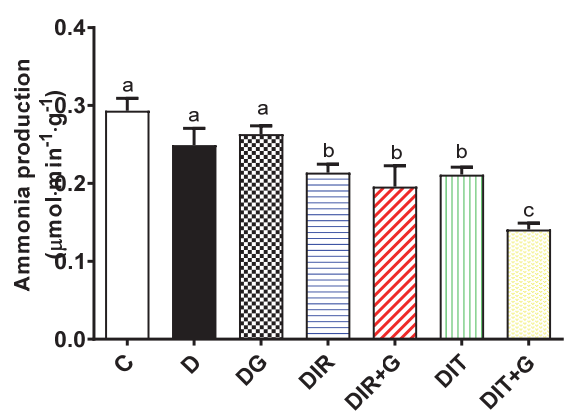

F Urea

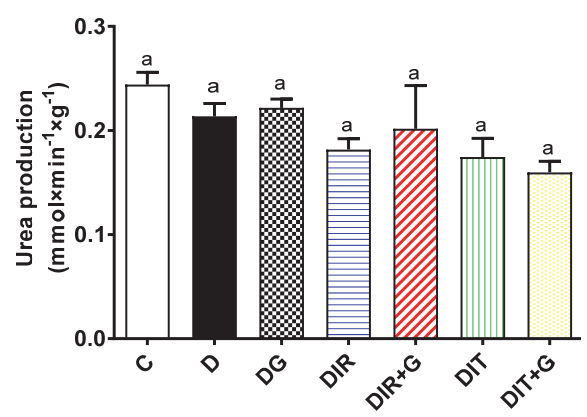

Fig. 4. Steady-state rates of metabolic fluxes derived from alanine metabolism in perfused livers of T1D mice during IIH. The steady-state rates achieved at 90 min perfusion time in the experiments shown in Fig. 2 were used to calculate the metabolic fluxes dependent solely on alanine transformation by subtracting the metabolic fluxes dependent on endogenous substrates. The abbreviations of the groups are defined in Table 1. Values are the mean \pm SEM of 5 animals. Values with different letters in the same panel are different $(p \leq 0.05)$. 

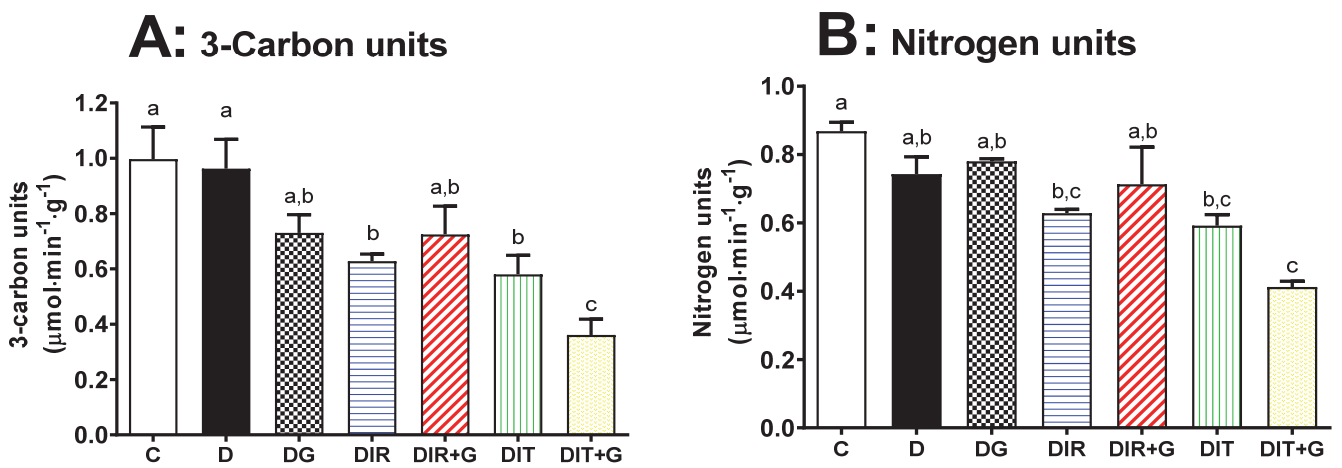

Fig. 5. Carbon and nitrogen fluxes derived from alanine in perfused livers of T1D mice during IIH. Data were computed from the data shown in Fig. 4. Carbon units: lactate + pyruvate $+2 \times$ glucose productions; Nitrogen units: ammonia $+2 \times$ urea productions. The abbreviations of the groups are defined in Table 1 . Values are the mean \pm SEM of 5 animals for each group. Values with different letters in the same panel are different $(p \leq 0.05)$.

Table 2. Morphometric analyses and serum transaminases activity

\begin{tabular}{|c|c|c|c|c|c|c|c|}
\hline Parameter & $C$ & $\mathrm{D}$ & DG & DIR & $\mathrm{DIR}+\mathrm{G}$ & DIT & $\mathrm{DIT}+\mathrm{G}$ \\
\hline Liver weight (g) & $1.9 \pm 0.1^{\mathrm{a}}$ & $2.3 \pm 0.1^{b}$ & $2.5 \pm 0.1^{b}$ & $1.7 \pm 0.1^{\mathrm{a}}$ & $2.8 \pm 0.1^{c}$ & $1.9 \pm 0.1^{a}$ & $2.7 \pm 0.1^{c}$ \\
\hline Number of hepatocytes $\left(\mathrm{mm}^{2}\right)^{-1}$ & $228 \pm 10^{\mathrm{a}}$ & $282 \pm 7^{b}$ & $284 \pm 10^{b}$ & $256 \pm 7^{c}$ & $235 \pm 6^{\mathrm{a}}$ & $297 \pm 4^{b}$ & $286 \pm 7^{b}$ \\
\hline Area of hepatocytes $\left(\mu \mathrm{m}^{2}\right)$ & $329 \pm 8^{a}$ & $384 \pm 13^{b}$ & $330 \pm 8^{\mathrm{a}}$ & $370 \pm 10^{\mathrm{b}}$ & $364 \pm 7^{b}$ & $328 \pm 14^{\mathrm{a}}$ & $332 \pm 7^{\mathrm{a}}$ \\
\hline AST (U/l) & $53 \pm 4^{\mathrm{a}}$ & $179 \pm 7^{\mathrm{b}}$ & $308 \pm 13^{c}$ & $381 \pm 10^{\mathrm{d}}$ & $261 \pm 4^{\mathrm{e}}$ & $34 \pm 6^{\mathrm{a}}$ & $35 \pm 2^{\mathrm{a}}$ \\
\hline $\operatorname{ALT}(\mathrm{U} / \mathrm{l})$ & $12 \pm 1^{\mathrm{a}}$ & $128 \pm 3^{\mathrm{b}}$ & $178 \pm 9^{c}$ & $173 \pm 5^{c}$ & $153 \pm 7^{c}$ & $24 \pm 1^{\mathrm{a}}$ & $12 \pm 1^{\mathrm{a}}$ \\
\hline
\end{tabular}

The abbreviations of the groups are defined in Table 1. Data represent the mean \pm standard error $(n=5)$. Values with different superscript letters in the same line are different $(p<0.05)$.

\section{Liver morphometry and serum transaminases activities}

The liver weight was not different for the C, DIR and DIT groups, but it was approximately $30 \%$ higher in the D, DG, DIR+G and DIT+G groups (Table 2). The results of the morphometric analyses are also listed in Table 2. The hepatocytes areas were $10-15 \%$ higher in the D, DIR and DIR+G groups and the hepatocytes number was approximately $25 \%$ higher in the D, DG, DIT and DIT+G mice when compared to C. The increase of the number of hepatocytes was lower for DIR $(+12 \%)$ and non-existent for DIR+G. The serum activities of transaminases were measured to evaluate if the morphometric modifications are related to liver damage. The AST activity was increased by $240 \%, 480 \%, 600 \%$ and $390 \%$, respectively, for D, DG, DIR and DIR+G when compared to C. The ALT activity was also increased in the same groups and the activities of both ALT and AST were not modified in DIT and DIT + G mice.

\section{Discussion}

\section{The glycemic response to IIH after GdiP and insulin degludec treatment}

In T1D individuals, recurrent episodes of hyper- and hypoglycemia take place as a consequence of inadequate insulin therapy or poor diet. In particular, the recurrent hypoglycemia has devastating effects on the well-being of individuals. This study used alloxan-induced T1D mice subjected to 30-day supplementation with GdiP in combination with degludec or regular insulins in an attempt to contribute to a better understanding of the phenomenon. The results show that blood glucose of $15 \mathrm{~h}$ fasted and untreated T1D mice drops sharply $60 \mathrm{~min}$ af- ter IIH and achieves values slightly above $50 \mathrm{mg} / \mathrm{dl}$ at $300 \mathrm{~min}$. This similar fact has also been found in patients and rodents with type 2 diabetes and T1D (Bataglini et al., 2017; Chakera et al., 2018). The blood glucose of fasted normoglycemic mice also drops sharply $60 \mathrm{~min}$ after IIH but it recovers almost completely after $300 \mathrm{~min}$ (Nunes Santiago et al., 2013). In the present study, only a relatively poor response to hypoglycemia was observed in T1D mice receiving cortisol. Thus, this model of IIH is similar to T1D patients with very low or no response to the hypoglycemic counterregulatory system (McCrimmon and Sherwin, 2010). Untreated T1D mice additionally presented increased serum transaminases. The latter phenomenon has also been reported for T1D patients and it is related to poorer glycemic control and even liver failure (Stadler et al., 2017).

Glutamine is the most abundant endogenous gluconeogenic precursor, and supplementation with this amino acid should relieve the hypoglycemia episodes (Cruzat et al., 2018). In our study, glutamine was orally administered as a dipeptide (GdiP). After absorption by the enterocytes it firstly passes through the liver where it can modify the hepatic response and contribute to glycemic recovery. GdiP, at the dose of $0.4 \mathrm{~g} / \mathrm{kg}$, is most commonly used for hospital treatment of catabolic individuals. However, doses as high as $1.0 \mathrm{~g} / \mathrm{kg}$ are not uncommon (Oguz et al., 2007). GdiP at the dose of $1.0 \mathrm{~g} / \mathrm{kg}$ is equivalent to $0.6 \mathrm{~g} / \mathrm{kg}$ of glutamine since this dipeptide (MW: 235) is composed of one molecule of glutamine (MW: 146) plus one molecule of alanine (MW: 89). The supplementation of T1D mice with GdiP did not improve fasting blood glucose or body weight gain, but it slightly attenuated the IIH at $60 \mathrm{~min}$, a phenomenon that was not maintained at 180-300 min. In this regard, glutamine orally administered at a dose of $0.1 \mathrm{~g} / \mathrm{kg}$ to normoglycemic mice after IIH has 
been associated with a greater ability to recover blood glucose (Nunes Santiago et al., 2013). However, the hepatic gluconeogenesis from glutamine or alanine of untreated mice during IIH is higher than in normoglycemic mice only when the liver is perfused with saturating levels of these substrates (12-16 mM) (Nunes Santiago et al., 2013). In addition, T1D mice receiving glutamine $(1 \mathrm{~g} / \mathrm{kg})$ shortly after IIH had a smaller fall of blood glucose at $60 \mathrm{~min}$, which was not maintained at 180-300 min and only occurred in association with cortisol (Bataglini et al., 2017).

T1D mice treated with insulin degludec provided better results than regular insulin in relation to parameters that were not modified by IIH, such as, for example, fasting blood glucose level and body weight gain. However, T1D mice treated with degludec had a more severe hypoglycemia at $60 \mathrm{~min}$ after IIH. This event was partly minimized by cortisol. In other words, mice treated with degludec may have preserved some response to the cortisol-linked counterregulatory system. Another difference was the serum transaminases. While insulin degludec reduced the activity of AST and ALT in T1D mice, regular insulin markedly increased the activity of both enzymes. In this regard, a transient elevation of serum transaminases after starting insulin therapy has been reported for T1D patients with ketosis or ketoacidosis related to poorly controlled diabetes and might imply severe dysfunction of glucose metabolism in the liver (Takaike et al., 2004, 2008). In fact, hyperglycemia and sustained levels of exogenous insulin are associated with hepatic glycogen overload and consequent liver damage in T1D (Giordano et al., 2014; Rajas et al., 2013). Elevated serum AST and ALT were also found in T1D rats 30-day treated with glutamine $(0.4 \mathrm{~g} / \mathrm{kg})$ alone or in combination with regular insulin (Azevedo, 2019).

\section{Alanine metabolism in mice livers after GdiP and insulin degludec treatment}

The results on alanine metabolism obtained with the perfused liver must be regarded in terms of medium- and long-term regulation under the conditions of the various treatments, i.e., modifications in the expression of enzymes and other molecules over time, which are preserved in the isolated organ. On the other hand, short-term regulation, as given by hormones such as glucagon and catecholamines, for example, reversibly acting allosteric effectors and in vivo substrate concentrations are absent because they are lost when the liver is removed. Consequently, the experiments are actually revealing the response of the enzymatic system as established just before the organ isolation. Substrate concentrations, for example, are different in vivo and in the perfused liver. The alanine concentration in vivo is much lower than the concentration used in the liver perfusion experiments $(5 \mathrm{mM})$. Even so, it is appropriate to analyze the compatibility between the in vivo and in vitro observations because the latter are likely to reflect medium- and long-term regulations.

Livers from D, DG and DIR+G mice present intense glycogenolysis just after starting perfusion. Intense glycogenolysis is the only explanation for the high rates of glucose output when perfusion is done in the absence of exogenous substrates because the contribution of endogenous substrates is minimal - as shown by several studies, which also reveal high levels of hepatic glycogen in T1D animals not injected with insulin (Comar et al., 2016; Gannon and Nuttall, 1997). Furthermore, high rates of glucose release when under substrate-free perfusion were absent in livers of DIR, a probable consequence of lower levels of glycogen induced by the insulin treatment. An even smaller output of glycogenolytic products tended to occur in livers from DIT and DIT+G. Singularly, the latter two groups are precisely those that present the lowest blood glucose after the $15 \mathrm{~h}$ fasting period, suggesting that a diminished glycogenolysis might have contributed to this. It is not the only cause, however, because livers from DIT and DIT+G also presented the lowest gluconeogenesis from alanine. Livers from DIR and DIR+G, on the other hand, which also presented high glycemic levels after a $15 \mathrm{~h}$ fast without accelerated glycogenolysis, had normal gluconeogenesis, suggesting that the latter was an important component for maintaining high glycemic levels.

The diminished gluconeogenesis of the DG mice group and of the DIT and DIT+G groups may have different causes if one looks at the rates of lactate production, which were high in the DG group and low in the DIT and DIT+G groups - actually very low for the latter. DIT and DIT+G presented lower rates of alanine transformation leading to lower rates of carbon and nitrogen fluxes. In contrast, the rate of alanine transformation in DG was high in terms of carbon and nitrogen fluxes, but a part of the amino acid was deviated into lactate production. These observations suggest that GdiP alone might have induced some limitation along the gluconeogenic pathway in spite of an efficient alanine transformation, whereas insulin degludec blocks alanine uptake in its initial steps. This conclusion must be regarded as highly preliminary and must be evidently confirmed by further experimentation.

\section{Liver morphometry after GdiP and insulin degludec treatment}

The supplementation of T1D mice with GdiP was followed by a significant increase in the serum transaminases activity and organ weight, phenomena that may be associated with liver glycogen overload. Glutamine is not only an effective amino acid for enhancing glycogen formation, but it has also been associated with the stimulation of glycogen synthetase (Cruzat et al., 2018; Stumvoll et al., 1999). In addition, T1D mice receiving GdiP in combination with both insulins presented higher levels of serum triglycerides. One possible justification is the increased availability of substrates is a consequence of GdiP supplementation associated with sustained levels of exogenous insulin.

With respect to the morphometric analyses, the increased liver weight was always associated with increased hepatocytes number and/or area. Glutamine is known to cause hepatocyte swelling that should increase the hepatocyte area. The latter was not found, but all groups that received GdiP presented higher liver weights, what might be due to higher glycogen content. In fact, the liver enlargement that occurs in B6C3F1 mice upon short-term exposure to dichloroacetic acid has been associated with liver hypertrophy due to increased glycogen content (Carter et al., 1995). In turn, T1D treated with GdiP + degludec had higher liver weight, but both glycogenolysis (and probably glycogen content) and serum transaminases were not increased. In any case, this study shows for the first time that the number and area of hepatocytes are increased in alloxan-induced T1D mice.

\section{Conclusions}

The 30-day treatment of T1D mice with insulin degludec, but not with regular insulin, improved fasting blood glucose, body weight gain and serum activity of AST and ALT. GdiP and both insulins at least minimally improved the IIH of T1D mice. Treatments with insulin degludec, GdiP and degludec + GdiP 
decreased the capacity of the liver in synthesizing glucose from alanine. These hypothetically beneficial effects must be regarded in conjunction with potentially adverse events. GdiP, in combination with both insulins, was associated with increases in the serum triglycerides, and regular insulin and GdiP increased the serum activity of AST and ALT, which seems to be a consequence of hepatic glycogen overload. Thus, the recommendation of long-term supplementation with $1 \mathrm{~g} / \mathrm{kg} \mathrm{GdiP}$ for T1D individuals should be viewed with caution, especially if associated with regular insulin.

\section{Ethical aspects and conflict of interests}

The authors have no conflicts of interest to declare. All of the authors have approved the final manuscript.

\section{Role of the funding source}

Conselho Nacional de Desenvolvimento Científico e Tecnológico (CNPq) and Coordenação de Aperfeiçoamento de Pessoal de Nível Superior (CAPES) had no involvement in the study design, the collection, analysis and interpretation of data, the writing of the report, nor the decision to submit the article for publication.

\section{Acknowledgements}

The authors wish to thank CAPES and CNPq for the financial support.

\section{References}

American Diabetes Association (2017). 8. Pharmacologic approaches to glycemic treatment. Diabetes Care 40(Suppl. 1): S64-S74. DOI: $10.2337 / \mathrm{dc} 17-\mathrm{s} 011$.

American Diabetes Association (2019). Pharmacologic approaches to glycemic treatment: standards of medical care in diabetes. Diabetes Care 42(Suppl. 1): S90-S102. DOI: 10.2337/dc19-S009.

Azevedo SCSF (2019). Efeitos da associação entre insulinoterapia e suplementação oral com l-glutamina sobre a morfofisiologia hepática de ratos wistar diabéticos tipo 1. Ph.D. Thesis (Postgraduate Program in Biological Sciences), State University of Maringá, PR, Brazil. [online] [cit. 2020-11-28]. Available at: http://repositorio.uem.br:8080/jspui/handle/1/5700

Bataglini C, Rezende DGL, Primo MA, Gomes CRG, Pedrosa MMD, Godoi VAF (2017). Glutamine dipeptide and cortisol change the liver glucose metabolism and reduce the severity of insulin-induced hypoglycaemia in untreated T1D Swiss mice. Arch Physiol Biochem 123(2): 134-144. DOI: 10.1080/13813455.2016.1273364.

Bergmeyer HU (1974). Methods of enzymatic analysis. London: Academic Press, 682 p.

Broetto-Biazon AC, Bracht F, Bracht L, Kelmer-Bracht AMK, Bracht A (2009). Transformation and action of extracellular NAD+ in perfused rat and mouse livers. Acta Pharmacol Sin 30(1): 90-97. DOI: 10.1038/aps.2008.7.

Carter JH, Carter HW, DeAngelo AB (1995). Biochemical, pathologic and morphometric alterations induced in male B6C3F1 mouse liver by short-term exposure to dichloroacetic acid. Toxicol Lett 81(1): 55-71. DOI: 10.1016/0378-4274(95)03409-9.

Castro-Ghizoni CV, Ames APA, Lameira OA, Bersani-Amado CA, Sá-Nakanishi AB, Bracht L, et al. (2017). Anti-inflammatory and antioxidant actions of copaiba oil are related to liver cell modifications in arthritic rats. J Cell Biochem 118(10): 34093423. DOI: $10.1002 / j c b .25998$.

Chakera AJ, Hurst PS, Spyer G, Ogunnowo-Bada EO, Marsh WJ, Riches $\mathrm{CH}$, et al. (2018). Molecular reductions in glucokinase activity increase counter-regulatory responses to hypoglycemia in mice and humans with diabetes. Mol Metab 17: 17-27. DOI: 10.1016/j.molmet.2018.08.001.
Comar JF, de Oliveira DS, Bracht L, Kemmelmeier FS, Peralta RM, Bracht A (2016). The metabolic responses to L-glutamine of livers from rats with diabetes types 1 and 2. PLoS One 11(8): e0160067. DOI: 10.1371/journal.pone.0160067.

Comar JF, Suzuki-Kemmelmeier F, Constantin J, Bracht A (2010). Hepatic zonation of carbon and nitrogen fluxes derived from glutamine and ammonia transformations. J Biomed Sci 17(1): 1. DOI: 10.1186/1423-0127-17-1.

Cruzat V, Macedo Rogero M, Noel Keane K, Curi R, Newsholme P (2018). Glutamine: metabolism and immune function, supplementation and clinical translation. Nutrients 10(11): 1564. DOI: $10.3390 /$ nu10111564.

Cryer PE (2008). The barrier of hypoglycemia in diabetes. Diabetes 57(12): 3169-3176. DOI: 10.2337/db08-1084.

Darmaun D, Torres-Santiago L, Mauras N (2019). Glutamine and type 1 diabetes mellitus: is there a role in glycemic control? Curr Opin Clin Nutr Metab Care 22(1): 91-95. DOI: 10.1097/ mco.0000000000000530.

Federiuk IF, Casey HM, Quinn MJ, Wood MD, Ward WK (2004). Induction of type- 1 diabetes mellitus in laboratory rats by use of alloxan: route of administration, pitfalls, and insulin treatment. Comp Med 54(3): 252-257. PMID: 15253270.

Gannon MC, Nuttall FQ (1997). Effect of feeding, fasting, and diabetes on liver glycogen synthase activity, protein, and mRNA in rats. Diabetologia 40(7): 758-763. DOI: $10.1007 /$ s001250050746.

Giordano S, Martocchia A, Toussan L, Stefanelli M, Pastore F, Devito A, et al. (2014). Diagnosis of hepatic glycogenosis in poorly controlled type 1 diabetes mellitus. World J Diabetes 5(6): 882-888. DOI: 10.4239/wjd.v5.i6.882.

Heise T, Hermanski L, Nosek L, Feldman A, Rasmussen S, Haahr H (2012). Insulin degludec: four times lower pharmacodynamic variability than insulin glargine under steady-state conditions in type 1 diabetes. Diabetes Obes Metab 14(9): 859-864. DOI: 10.1111/j.1463-1326.2012.01627.x.

Jonassen I, Havelund S, Hoeg-Jensen T, Steensgaard DB, Wahlund P-O, Ribel U (2012). Design of the novel protraction mechanism of insulin degludec, an ultra-long-acting basal insulin. Pharm Res 29(8): 2104-2114. DOI: 10.1007/s11095-0120739-z.

McCrimmon RJ, Sherwin RS (2010). Hypoglycemia in type 1 diabetes. Diabetes 59(10): 2333-2339. DOI: 10.2337/db10-0103.

Nunes Santiago A, de Godoi-Gazola VAF, Milani MF, de Campos VC, Rodrigues Vilela V, Diaz Pedrosa MM, Bazotte RB (2013). Oral glutamine is superior than oral glucose to promote glycemia recovery in mice submitted to insulin-induced hypoglycemia. Int J Endocrinol 2013: 841514. DOI: 10.1155/2013/841514.

Oguz M, Kerem M, Bedirli A, Mentes BB, Sakrak O, Salman B, Bostanci H (2007). L-Alanin-L-glutamine supplementation improves the outcome after colorectal surgery for cancer. Colorectal Dis 9(6): 515-520. DOI: 10.1111/j.14631318.2006.01174.x.

Prasath GS, Pillai SI, Subramanian SP (2014). Fisetin improves glucose homeostasis through the inhibition of gluconeogenic enzymes in hepatic tissues of streptozotocin induced diabetic rats. Eur J Pharmacol 740: 248-254. DOI: 10.1016/j. ejphar.2014.06.065.

Raizel R, Tirapegui J (2018). Role of glutamine, as free or dipeptide form, on muscle recovery from resistance training: a review study. Nutrire 43: 28. DOI: 10.1186/s41110-018-0087-9.

Rajas F, Labrune P, Mithieux G (2013). Glycogen storage disease type 1 and diabetes: Learning by comparing and contrasting the two disorders. Diabetes Metab 39(5): 377-387. DOI: 10.1016/j. diabet.2013.03.002.

Reagan-Shaw S, Nihal M, Ahmad N (2007). Dose translation from animal to human studies revisited. FASEB J 22(3): 659-661. DOI: 10.1096/f.07-9574LSF.

Sharabi K, Tavares CDJ, Rines AK, Puigserver P (2015). Molecular pathophysiology of hepatic glucose production. Mol Aspects Med 46: 21-33. DOI: 10.1016/j.mam.2015.09.003.

Sies H (1982). Nicotinamide nucleotide compartmentation. In: Sies H (Ed.). Metabolic Compartmentation. New York: Academic Press, pp. 205-231. 
Silver B, Ramaiya K, Andrew SB, Fredrick O, Bajaj S, Kalra S, et al. (2018). EADSG Guidelines: insulin therapy in diabetes. Diabetes Ther 9(2): 449-492. DOI: 10.1007/s13300-018-0384-6.

Stadler M, Bollow E, Fritsch M, Kerner W, Schuetz-Fuhrmann I, Krakow D, et al. (2017). Prevalence of elevated liver enzymes in adults with type 1 diabetes: A multicentre analysis of the German/ Austrian DPV database. Diabetes Obes Metab 19(8): 1171-1178. DOI: $10.1111 /$ dom.12929.

Stehle P, Ellger B, Kojic D, Feuersenger A, Schneid C, Stover J, et al. (2017). Glutamine dipeptide-supplemented parenteral nutrition improves the clinical outcomes of critically ill patients: A systematic evaluation of randomized controlled trials. Clin Nutr ESPEN 17: 75-85. DOI: 10.1016/j.clnesp.2016.09.007.

Stumvoll M, Perriello G, Meyer C, Gerich J (1999). Role of glutamine in human carbohydrate metabolism in kidney and other tissues. Kidney Int 55(3): 778-792. DOI: 10.1046/j.15231755.1999.055003778.x.

Takaike H, Uchigata Y, Iwamoto Y, Imagawa A, Iwahashi H, Kanatsuka A, et al. (2008). Nationwide survey to compare the prevalence of transient elevation of liver transaminase during treatment of diabetic ketosis or ketoacidosis in new-onset acute and fulminant type 1 diabetes mellitus. Ann Med 40: 395-400. DOI: 10.1080/07853890802032711.

Takaike H, Uchigata Y, Iwasaki N, Iwamoto Y (2004). Transient elevation of liver transaminase after starting insulin therapy for diabetic ketosis or ketoacidosis in newly diagnosed type 1 diabetes mellitus. Diabetes Res Clin Pract 64(1): 27-32. DOI: 10.1016/j. diabres.2003.10.017. 